\title{
Bacterial Lipopolysaccharide-induced Intestinal Microvascular Lesions Leading to Acute Diarrhea
}

\author{
V. I. Mathan, ${ }^{\star}$ G. R. Penny, ${ }^{\ddagger}$ M. M. Mathan, ${ }^{*}$ and D. Rowley ${ }^{\ddagger}$ \\ *The Wellcome Research Unit, Christian Medical College Hospital, Vellore, 632 004, India; ${ }^{\ddagger}$ The Department \\ of Microbiology and Immunology, The University of Adelaide, Adelaide 5001, South Australia
}

\begin{abstract}
Subcutaneous challenge of mice with lipopolysaccharide (LPS) from gram negative bacteria, produced an intestinal microvascular lesion causing fluid exudation into the lumen of the intestine and diarrhea. The microvascular lesion was characterized by endothelial cell damage and microthrombi in the venules and capillaries of the intestinal lamina propria. Marker organisms, given orally to challenged mice, grew in the exuded fluid and could invade the mucosa. Intravenous transfer of postchallenge plasma produced the lesion in normal mice and absorption of such plasma by Sepharose coupled to LPS-antibody abolished this effect. Instillation of large quantities of LPS into the lumen of the intestine produced scattered microvascular lesions, although none of these animals developed diarrhea. Since a similar microvascular lesion has been described in the rectal mucosal lamina propria of adults with acute diarrhea, it is suggested that LPS-induced vascular damage may be a novel mechanism in the pathogenesis of acute diarrhea.
\end{abstract}

\section{Introduction}

The strategy of oral maintenance of hydration can significantly reduce the mortality associated with acute diarrheal disease, but does not change the morbidity and consequent economic losses. A fuller understanding of enteric pathogens and pathogenic mechanisms is therefore necessary for the control of this major public health problem. The two well characterized mechanisms of pathogenesis, enterotoxins and tissue invasion, account for only a small proportion of patients with diarrhea and microbial enteric pathogens cannot be identified in stool samples from 20 to $40 \%$ of patients (1). Recognized microbial enteric pathogens can be isolated from the stools of up to a third of apparently healthy asymptomatic individuals resident in many tropical developing countries (2-5). This wide prevalence of enteric pathogens in asymptomatic individuals does not appear to increase their resistance to diarrhea, since its endemicity and consequent mortality continue to be high in such areas. These findings suggest that there must be as yet unrecognized enteric pathogens or novel mechanisms of pathogenesis of diarrhea.

Address reprint requests to Dr. V. I. Mathan, The Wellcome Research Unit, Christian Medical College Hospital, Vellore 632 004, India. Received for publication 7 April 1987 and in revised form 16 May 1988.

J. Clin. Invest.

(c) The American Society for Clinical Investigation, Inc.

$0021-9738 / 88 / 11 / 1714 / 08 \$ 2.00$

Volume 82, November 1988, 1714-1721
The host response to acute diarrhea may reveal valuable clues regarding mechanisms of pathogenesis. Rectal mucosal biopsies and detailed studies to identify etiologic agents were carried out in a group of adults with acute diarrhea in southern India (6). A microvascular lesion in the rectal mucosal lamina propria capillaries and venules, with endothelial cell damage and focal hemorrhages was detected in many of these patients. The prevalence of these lesions correlated with the clinical severity of diarrhea, but not with the presence or type of enteric pathogen (6). Although it was not clear whether this vascular lesion was causal or secondary to diarrhea, it appeared likely to be the result of vascular injury by bacterial LPS (7). The capillaries and venules of the intestine would normally be sensitized to LPS, as it is absorbed in minute quantities from the gram negative flora that colonizes the gut lumen $(8,9)$ and further exposure to LPS could lead to vascular damage (10). Other studies aimed at understanding the pathogenesis and immunity to Salmonellosis in mice orally infected with Salmonellae, showed that fluid accumulated in the lumen of the bowel within $4 \mathrm{~h}$ of subcutaneous challenge with a crude preparation of Salmonella outer membrane protein (11). The outer membrane protein preparations contain LPS and it was likely that LPS mediated vascular endothelial damage, of lamina propria blood vessels sensitized by LPS of Salmonellae, may have been responsible for the fluid exudation. This animal model appeared to be relevant to studies on the pathogenesis of acute diarrhea, in view of the finding of an LPS-induced vascular lesion in patients in southern India $(6,7)$. A detailed study of this animal model is reported here and its possible clinical implications are discussed.

\section{Methods}

Animals. 6-8-wk-old, specific pathogen free (SPF) ${ }^{1}$ LAC strain mice and rabbits for raising antisera, were supplied by the Central Animal House of the University of Adelaide. Where appropriate, the mice were conventionalized in the Departmental Animal House, on commercial mouse chow and tap water, for at least 2 wk until gram negative fecal flora developed.

Bacterial strains. Salmonella 885 is a Salmonella typhimuriumEscherichia coli hybrid strain derived from a cross between $S$. typhimurium SF1142 and E. coli $\mathrm{Hfr} 492$. It expresses $E$. coli 08 antigens and when given orally to mice colonizes the Peyer's patches for several weeks without causing illness (12). A streptomycin-resistant mutant of this strain, designated $885 \mathrm{SR}$, and other streptomycin-resistant bacteria were obtained from type cultures maintained in the department.

Bacterial lipopolysaccharides. LPS was prepared from overnight broth cultures of $S$. typhimurium strain C5 (C5LPS) Salmonella 885 (885LPS), Vibrio cholera strain 569B (569BLPS), and Shigella flexneri (SFLPS), by the phenol/water extraction technique (13). The final

1. Abbreviations used in this paper: OMP, outer membrane proteins; SPF, specific pathogen free. 
precipitate of LPS was solubilized in distilled water and stored lyophilized at $-20^{\circ} \mathrm{C}$ in 2-mg aliquots. Protein content of this preparation was $<2 \%$ of the dry weight and it was free of cytotoxic activity in a Vero cell assay (14).

Whole outer membrane preparations (OMP). OMP or cell walls were prepared from Bacteroides fragilis (grown anaerobically for $72 \mathrm{~h}$ on blood agar with 5\% normal horse serum), Haemophilus influenzae (grown on chocolate agar incubated in $5 \% \mathrm{CO}_{2}$ in air), Lactobacillus plantorum, Bacillus cereus, Salmonella typhimurium C5, and Salmonella 885 (broth cultures). Washed bacteria were suspended in $20 \mathrm{ml}$,

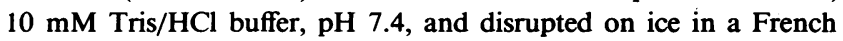
Press. The disrupted bacterial suspension was centrifuged at $7 \mathrm{~K}$ for 10 min in a Sorvall RC5C refrigerated centrifuge (Sorvall Instrument Co., Inc., Newton, CT). The supernatant was sedimented at $78,000 \mathrm{~g}$ for 90 min at $4^{\circ} \mathrm{C}$ in a $55.2 \mathrm{Ti}$ rotor in an ultracentrifuge (L8.70; Beckman Instruments, Inc., Palo Alto, CA) and the resultant supernatant discarded. The pellet was resuspended in $30 \mathrm{ml}$ of distilled water and again sedimented as above. The pellet from the second centrifugation was resuspended in $5 \mathrm{ml}$ of distilled water and stored frozen after determining the dry weight of an aliquot.

Oral infection of mice, LPS challenge, and recovery of organisms. Mice were infected with bacterial suspensions of $5 \times 10^{8}$ live organisms in $0.2 \mathrm{ml}$ of nutrient broth through a blunt curved $19 \mathrm{~g}$ needle introduced transorally into the stomach. Gastric acid was neutralized by giving $0.2 \mathrm{ml}$ of half-saturated sodium bicarbonate $5 \mathrm{~min}$ before the administration of organisms.

In most LPS challenge experiments SPF mice, preconditioned with oral 885 SR infection a week earlier, were given $50 \mu \mathrm{g}$ of LPS or OMP preparations in $0.2 \mathrm{ml}$ of sterile pyrogen-free saline as a single subcutaneous injection in the flank. In some experiments, especially in conventionalized animals, the challenge was given at the same time as oral infection with a marker organism. Dilutions of LPS or OMP were prepared fresh, sonicated, and kept on ice until given. The effect of the challenge was monitored by comparing, with batch mates challenged with subcutaneous pyrogen free saline, the appearance of the mice, fecal staining of anal fur, fluid distension, and histopathological changes in the small intestine and colon and quantitative recovery of marker bacteria from the bowel. The challenged mice who developed diarrhea, appeared sick with ruffled fur, had distension and vascular lesions in the small intestines and colon, and the recovery of marker bacteria from the intestinal walls was enhanced $1 \log ^{10}$ or more. The enhancement of bacterial growth in the intestinal walls was used as a quantitative measure of the response to the challenge.

For quantitative recovery of bacteria, mice were killed by cervical dislocation and the small and large intestines removed rapidly without spilling the contents. Intestinal luminal contents were washed out with $2 \mathrm{ml}$ of ice-cold saline. The intestines were further washed with $10 \mathrm{ml}$ of ice-cold saline to remove adherent bacteria. The luminal contents and the washed bowel were separately homogenized with an Ultraturrax homogenizer (Janke and Kunkel, West Germany) and dilutions plated on appropriate solid media containing streptomycin. Mean values were calculated for groups of four or five control and LPS-challenged mice.

Histopathological examinations. The entire small and large intestines were examined from three preconditioned SPF mice without LPS challenge and three mice each, 4,8 , and $24 \mathrm{~h}$ after challenge with $50 \mu \mathrm{g}$ C5LPS. The intestines were removed, quickly flushed with $10 \%$ buffered formalin, opened lengthwise along the antimesenteric border and rolled carefully on an orange stick in a bath of $10 \%$ formalin. The upper end of the small intestine, or the appendix in the case of the large bowel, was always at the inner end of the roll. After at least $48 \mathrm{~h}$ of fixation in formalin, the tissues were processed, embedded in paraffin, and sections stained with hematoxylin and eosin. It was possible to examine the entire length of the intestine in these sectioned rolls. Tissues from liver, spleen, kidney, lung, and stomach were also examined, from these mice and also from normal mice challenged with 2 and $10 \mu \mathrm{g}$ of C5LPS. In all other experiments a $1-\mathrm{cm}$ segment of the upper small intestine, including the first visible Peyer's patch, was obtained from three controls and three mice in each challenge group for histopathological examination.

Dose-response experiments. The amount of C5LPS necessary to produce microvascular lesions and diarrhea was determined in SPF mice, conventionalized mice, and mice preconditioned with $885 \mathrm{SR}$ oral infection a week earlier. 885SR was given transorally at the time of the LPS challenge as a marker organism in mice that were not preconditioned. Based on the results of preliminary experiments, 2, 5, 10, 50, and $100 \mu \mathrm{g}$ of C5LPSS were given subcutaneously as single injections to all groups. In addition 200- and 500- $\mu$ g doses were also used in SPF mice. Intravenous dose response was determined in preconditioned SPF mice by giving three injections into the tail vein, at hourly intervals, of $2,5,10$, and $100 \mathrm{ng}$ and $1 \mu \mathrm{g}$ of C5LPS, as well as single injections of $10 \mu \mathrm{g}$.

Passive transfer. Blood was collected into citrated tubes from the retroorbital plexus of mice under ether anesthesia and the plasma separated on ice. Initial experiments showed that pooled plasma obtained within $2 \mathrm{~h}$ of $50 \mu \mathrm{g}$ LPS challenge, when given as three separate intravenous injections at hourly intervals to preconditioned mice produced the most marked effect. Plasma was pooled from 12 mice, each bled at 20 and 40,60 and 80 , and 100 and 120 min after subcutaneous LPS challenge. $0.6-0.8 \mathrm{ml}$ of the pooled plasma was given sequentially into the tail vein of $885 \mathrm{SR}$ preconditioned mice at time $0(20-40-\mathrm{min}$ pool), $60 \mathrm{~min}$ (60-80-min pool) and $120 \mathrm{~min}$ (100-120-min pool). The animals were observed and killed at $24 \mathrm{~h}$ for histopathology and recovery of $885 \mathrm{SR}$. Controls were either not challenged or were given sterile pyrogen-free saline, fresh SPF mouse plasma or $885 \mathrm{SR}$ preconditioned SPF mouse plasma intravenously. To determine whether the response to postchallenge plasma was due to LPS, an aliquot of each pool was absorbed on minicolumns of Sepharose IVB coupled to antibody to C5LPS before intravenous administration. The plasma after this absorption did not contain detectable amounts of LPS.

LPS antibodies. Antibodies to C5LPS, 885LPS, Salmonella minnesota strain $218 \mathrm{~S}$ (smooth LPS strain), and the rough variant R595 were raised in rabbits and crude IgG fractions were prepared by ammonium sulfate precipitation. Lipid A was prepared from C5LPS by acid hydrolysis and coupled to bovine serum albumin for raising antibodies in rabbits. LPS-antibody complexes were prepared in vitro using excess antibody and recovered at $90,000 \mathrm{~g}$ for $90 \mathrm{~min}$. Mice were challenged subcutaneously with various LPS-antibody complexes containing 50 $\mu \mathrm{g}$ of LPS, LPS alone, or LPS subcutaneously and antibody intravenously at the same time or half an hour before LPS challenge. LPS was also reacted with polymyxin $B$, which specifically inactivates the lipid A moiety of LPS, prior to subcutaneous challenge.

The effect of C5LPS challenge on bacterial infection. To determine whether enhancement of bacterial growth subsequent to C5LPS challenge occurred only with Salmonellae, groups of 10 conventionalized mice were infected orally with $5 \times 10^{8}$ live organisms of $S$. typhimurium C5, S. typhimurium LT2, Vibrio cholera 569B, Shigella flexneri, $H$. influenzae, L. plantorum, and Bacteroides fragilis and half of each group was challenged with $50 \mu \mathrm{g}$ of C5LPS within half an hour. The organisms, which were all streptomycin-resistant mutants, were quantitated from the lumen and walls of the small intestine and colon $24 \mathrm{~h}$ later in challenged and control mice.

Challenge with other LPS and OMP preparations. In addition to C5LPS, preparations of LPS from Salmonella 885, V. cholera 569B, and Shigella flexneri and OMP from $S$. typhimurium C5, Salmonella $885, H$. influenzae, Bacillus cereus, L. plantorum, and Bacteroides fragilis were used to challenge $885 \mathrm{SR}$ preconditioned mice. The recovery of 885SR from the wall of the small intestine was determined $24 \mathrm{~h}$ after the challenge. The $S$. typhimurium C5 OMP preparations contained $\sim 30 \%$ by weight of C5LPS when assayed by hemagglutination inhibition.

Enteral challenge with C5LPS. Diarrhea in humans is unlikely to be caused by the parenteral entry of LPS. However, LPS is normally absorbed from the gastrointestinal tract of mice and humans $(8,9)$. We therefore decided to see if a lesion could be induced by enteral administration of C5LPS. 885SR preconditioned mice were given 0.5 or 1.0 
mg of C5LPS, either transorally into the stomach or by enema. Bacterial growth was quantitated in challenged mice $24 \mathrm{~h}$ later. In some challenged mice the entire small and large intestines were processed for histopathological examination.

\section{Results}

C5LPS challenge produced an intestinal microvascular lesion and diarrhea. $4 \mathrm{~h}$ after subcutaneous challenge of 885SR preconditioned SPF mice with $50 \mu \mathrm{g}$ C5LPS, the small and large intestinal walls were congested, and the lumen contained bilestained fluid and gas bubbles. 8 and $24 \mathrm{~h}$ after the challenge there were scattered petechial hemorrhages on the bowel wall and distension of the small intestine by fluid had increased. The colon contained only liquid feces and the anal fur was usually stained by feces (Fig. 1). Histologically, $4 \mathrm{~h}$ after C5LPS challenge congestion, vascular endothelial cell damage and loss of endothelial cells was present in almost all the capillaries and venules of the small intestinal and colonic lamina propria (Fig. 2). The endothelial cell damage was more apparent $8 \mathrm{~h}$ after the C5LPS challenge and at $24 \mathrm{~h}$ vascular occlusion by microthrombi was present in many capillaries and venules. Neutrophils were present adjacent to and infiltrating blood vessels. At $24 \mathrm{~h}$, there was marked depletion of mucus from goblet cells and few scattered foci of epithelial exfoliation especially in distended loops of bowel. In mice challenged with $50 \mu \mathrm{g}$ or more C5LPS, marked fatty change in the liver with vascular endothelial cell damage in the liver, kidneys, and spleen was observed. This damage did not occur with $2 \mu \mathrm{g}$ C5LPS and minimal liver damage was present when $10 \mu \mathrm{g}$ C5LPS was used. There was extensive vascular damage in the small bowel with C5LPS challenge at doses of $10 \mu \mathrm{g}$ or more.

Recovery of 885SR was enhanced 24 h after C5LPS challenge. As reported earlier $(11,12), 885 \mathrm{SR}$ colonized the lumen and wall of the small intestine after transoral infection. Quantitative recovery of $885 \mathrm{SR}$ was maximal on day 3 or 4 postin- fection, with progressive decrease in the number of organisms recovered thereafter up to the 43rd d after infection (Fig. 3). After subcutaneous challenge with C5LPS on days 7, 14, 28, and 42 postoral infection with $885 \mathrm{SR}$, fluid accumulation in the lumen of the bowel and diarrhea with fecal staining of anal fur was associated with increased recovery of 885SR from the bowel wall $24 \mathrm{~h}$ later. The enhanced recovery of a marker organism was a consistent finding in all experiments and appeared to reflect the severity of the vascular lesion and fluid exudation.

The response to parenteral C5LPS was dose related and dependent on the presence of gram negative intestinal flora. 885SR preconditioned SPF mice challenged $7 \mathrm{~d}$ later with subcutaneous C5LPS at dose levels of $0.5,1.0$, or $2.0 \mu \mathrm{g}$ did not become sick or develop enhancement of bacterial growth, although intestinal vascular endothelial damage occurred in scattered vessels of the small intestine of mice injected with 2 $\mu \mathrm{g}$. Two of five mice given $10 \mu \mathrm{g}$ and all mice challenged with 50 or $100 \mu \mathrm{g}$ had intestinal fluid accumulation and enhanced bacterial growth (Fig. 4). The response of conventionalized mice was similar, whether or not they were preconditioned with 885 SR (Table I). In SPF mice on the day of delivery from the SPF unit, challenge with $50 \mu \mathrm{g}$ C5LPS caused vascular damage in a few lamina propria blood vessels, but they did not develop diarrhea. Fluid accumulation and bacterial growth enhancement occurred only with challenge doses of $200 \mu \mathrm{g}$ C5LPS. A single intravenous injection of $10 \mu \mathrm{g}$ of C5LPS produced fluid accumulation in 885SR preconditioned SPF mice. However, three intravenous injections of $10 \mathrm{ng}$ C5LPS at hourly intervals also caused fluid accumulation with enhanced bacterial recovery in two of five mice (Table I).

Transfer of postchallenge plasma induced the lesion. Microvascular lesions, luminal fluid accumulation and enhanced bacterial growth occurred in $885 \mathrm{SR}$ preconditioned mice challenged intravenously with pooled plasma collected after C5LPS subcutaneous challenge of $885 \mathrm{SR}$ preconditioned

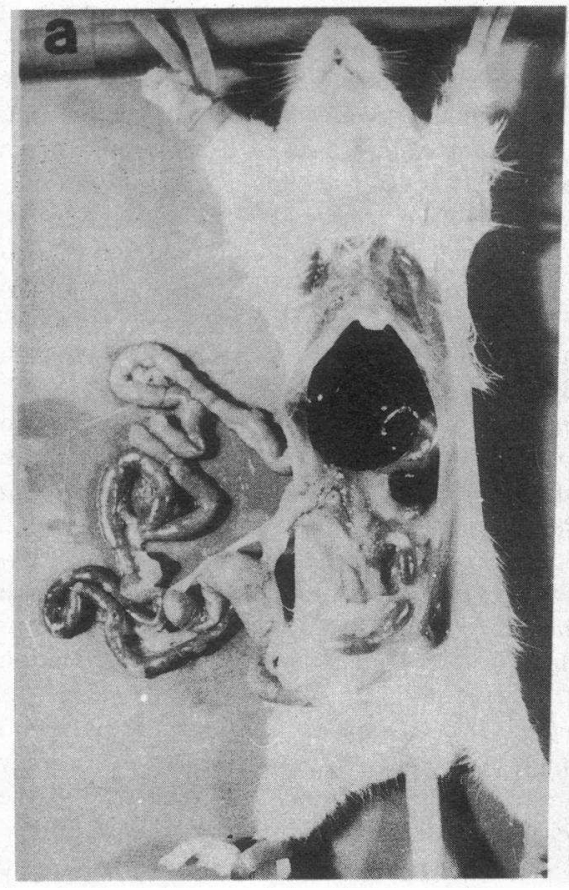

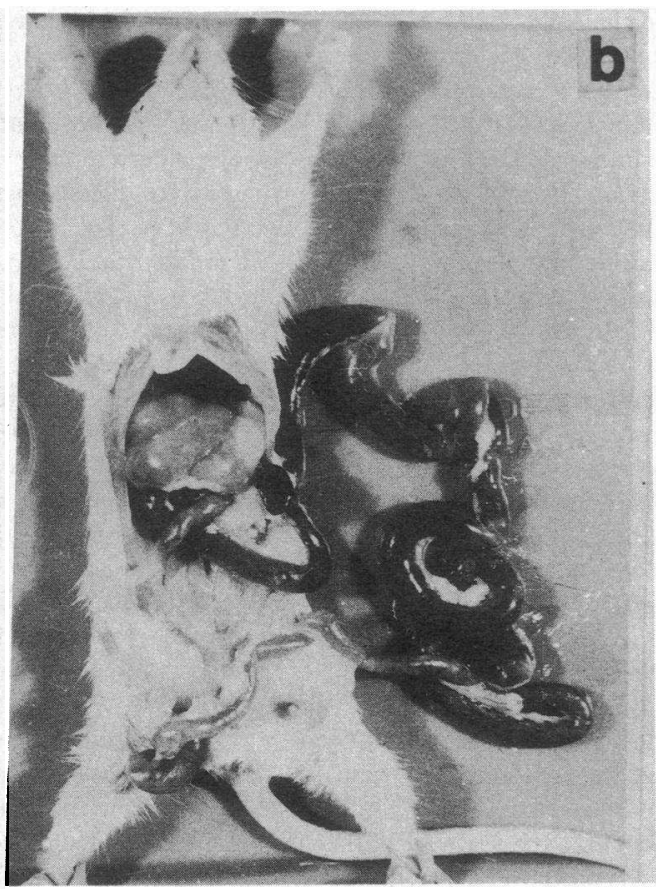

Figure 1. Appearance of intestinal tract in 885SR infected mice. (a) Control. Note normal intestine with fecal pellets in colon. (b) $24 \mathrm{~h}$ after $50 \mu \mathrm{g}$ of C5LPS S.C. The small intestine is distended with fluid and gas. There are no fecal pellets in the colon filled with fluid feces. 

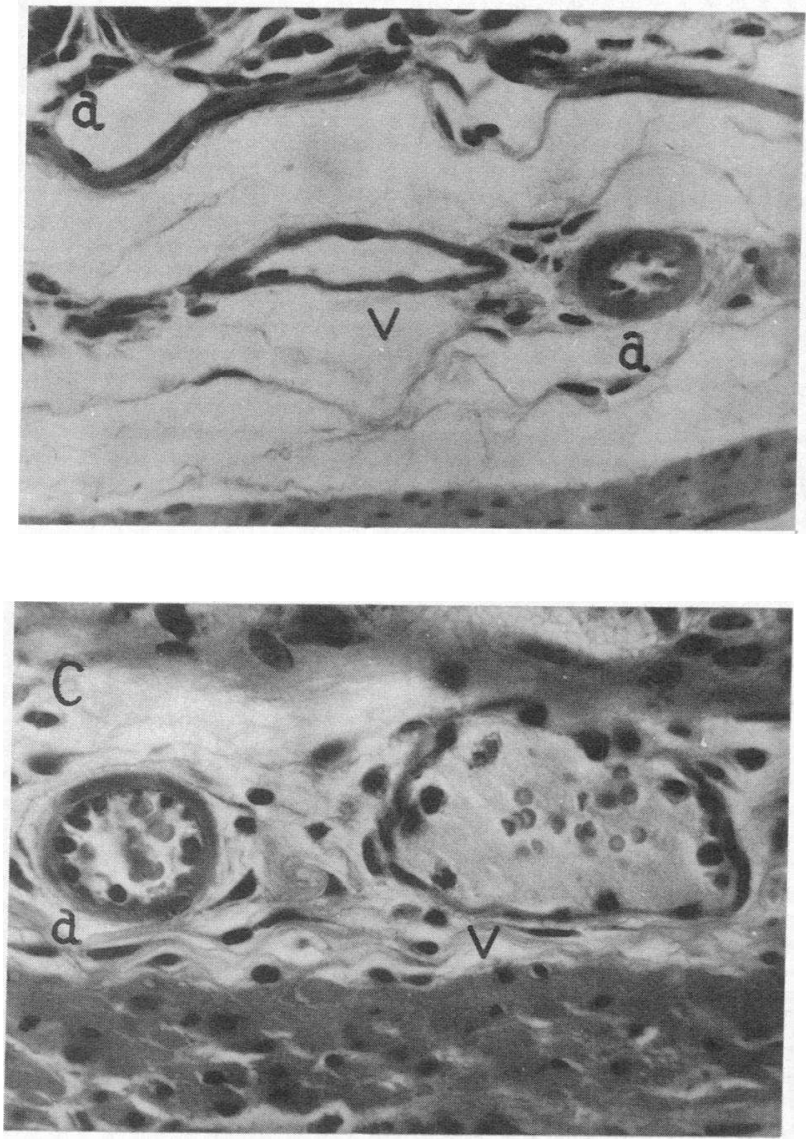

Figure 2. Effect of Salmonella C5 LPS on blood vessels of the mouse intestinal wall. Venules $(v)$, Arterioles $(a)$. All photomicrographs at the same magnification (470). (a) Control. Note venule and adjacent arteriole with normal endothelial lining. (b) $4 \mathrm{~h}$ after parenteral LPS. Note distended congested venule with clumping of red blood cells and absence of endothelial nuclei. Arteriole appears intact. (c) $8 \mathrm{~h}$ after parenteral LPS. The blood vessels are congested and distended
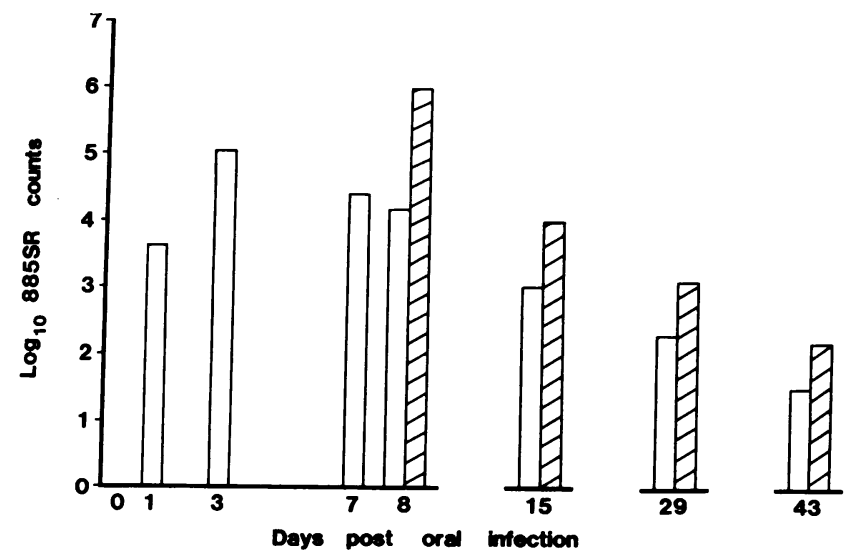

Figure 3. Colonization of the small intestinal wall by Salmonella 885 (streptomycin resistant) following $5 \times 10^{8}$ organisms given to SPF mice on day 0 . Note maximum recovery on day 3 and decline thereafter (open columns unchallenged counts). Infection persists up to day 43 . On day $7,14,28$, and 42 postoral infection, groups of five mice were challenged with $50 \mu \mathrm{g}$ C5LPS. The bacterial recovery in small intestinal wall (hatched columns) was increased compared to unchallenged controls $24 \mathrm{~h}$ later. Each bar was the mean of experiments on groups of five mice. The variability was $<5 \%$.
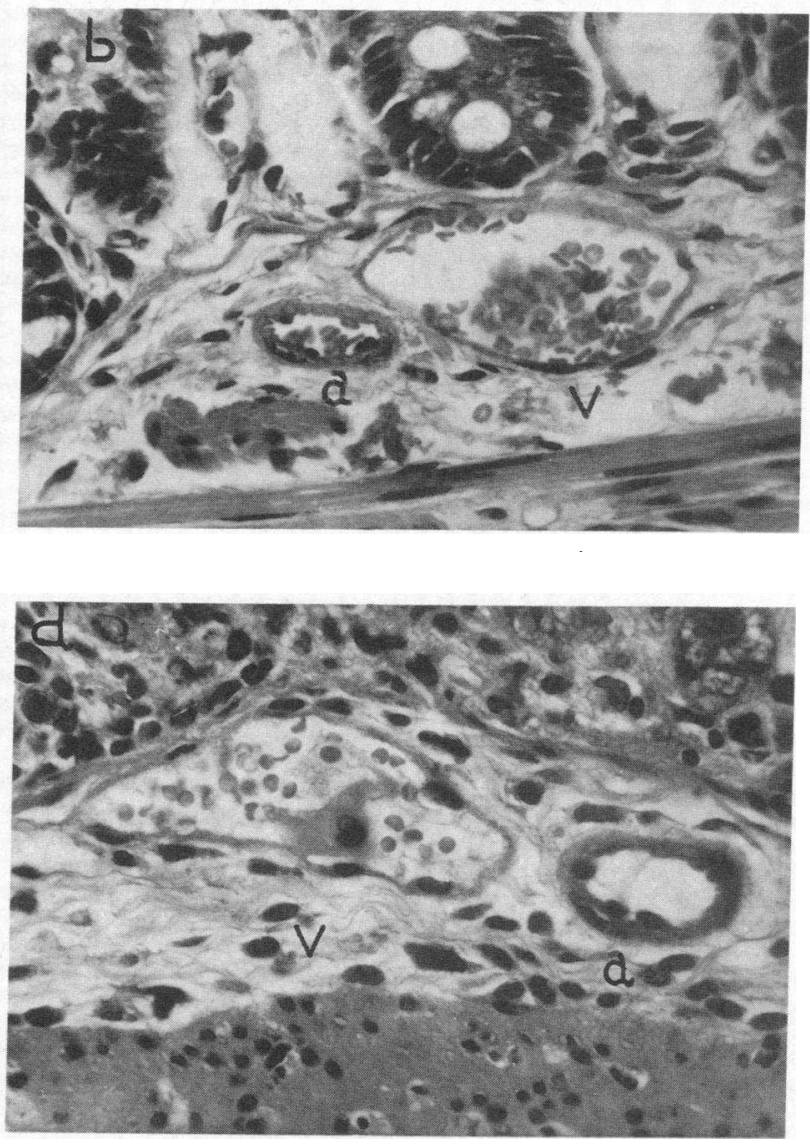

and the endothelial nuclei are large, rounded, and detached from the wall in the venule. The homogeneous appearance in the lumen suggests a fibrin thrombus. The arteriole is slightly distended but the endothelium appears normal. (d) $24 \mathrm{~h}$ after parenteral LPS. The abnormalities in the venule are persistent with homogeneous material suggesting fibrin thrombus. The arteriole is still apparently unaffected.

mice, given as three separate infusions at 60 -min intervals (Fig. 5). When the plasma pools were absorbed with Sepharose IVB coupled to antibody to C5LPS, recipient 885 SR preconditioned mice were unaffected (Fig. 5).

Antibodies to LPS blocked the effect of LPS challenge. Subcutaneous administration of LPS as an LPS-antibody complex reduced its effect in mice (Fig. 6). Blocking was effective when antibody was given intravenously to mice at the same time as, or half an hour earlier than the LPS challenge. Antibodies directed against LPS of other serotypes (e.g., anti-S. minnesota $218 \mathrm{~S}$ or R595) or antibody to lipid A, were effective in blocking (Table II). Similarly, reacting C5LPS with polymyxin B in vitro blocked its ability to produce vascular lesions and diarrhea (Table II).

Subcutaneous C5LPS challenge enhanced the growth of a variety of bacteria in the bowel. Enhanced recovery of luminal bacteria after LPS challenge was not confined to Salmonellae, since the recovery of $V$. cholera 569B, Shigella flexneri, $H$. influenzae, L. plantorum, and Bacteroides fragilis was also increased $24 \mathrm{~h}$ after C5LPS challenge, when the challenge immediately followed transoral administration of the bacteria (Table III). Luminal fluid accumulation and microvascular lesions occurred in all challenged animals. 


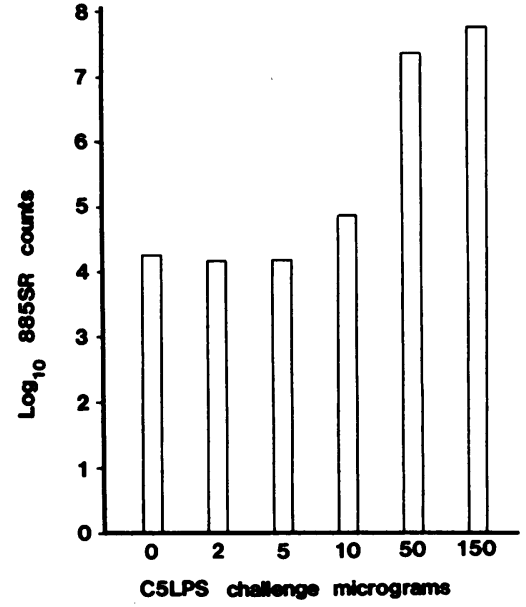

LPS and OMP from gram negative bacteria caused microvascular lesions. Microvascular lesions, luminal fluid accumulation and enhancement of growth of 885SR, were consistently produced by challenging $885 \mathrm{SR}$ preconditioned mice with LPS or OMP from Salmonella $885, S$. typhimurium C5 or LT2, LPS from $V$. cholera 569B, and $S$. flexneri and OMP from $H$. influenzae (Table IV). Cell walls prepared from $B a$ cillus cereus, $L$. plantorum, and Bacteroides fragilis did not affect the mice.

Large amounts of C5LPS given enterally induced the vascular lesion. Intestinal luminal fluid accumulation or enhanced bacterial recovery was not found in any 885SR preconditioned mice given 0.5 or $1.0 \mathrm{mg}$ of C5LPS intragastric or by enema. However, histopathological examination of entire

Table I. Dose Response of Mice to Parenteral LPS Challenge

\begin{tabular}{|c|c|c|c|c|}
\hline Type of mice & $\begin{array}{l}\text { Route of } \\
\text { challenge }\end{array}$ & $\begin{array}{l}\text { Dose of LPS } \\
\text { causing } \\
\text { lesion in at } \\
\text { least } 2 / 5 \\
\text { mice }\end{array}$ & $\begin{array}{l}\text { Dose } \\
\text { producing } \\
\text { lesion in } \\
\text { all mice } \\
\text { in group }\end{array}$ & $\begin{array}{c}\text { Mean } \\
\text { enhancement } \\
\text { of bacterial } \\
\text { growth over } \\
\text { unchallenged } \\
\text { controls }\end{array}$ \\
\hline & & $\mu g$ & $\mu g$ & $\log _{10}$ counts \\
\hline SPF & Subcutaneous & 50 & 200 & 3.13 \\
\hline Preconditioned & & & & \\
\hline SPF & Subcutaneous & 10 & 50 & 3.14 \\
\hline $\begin{array}{l}\text { Conventional } \\
\text { (CON) }\end{array}$ & Subcutaneous & 10 & 50 & 2.97 \\
\hline Preconditioned & & & & \\
\hline $\mathrm{CON}$ & Subcutaneous & 10 & 50 & 3.03 \\
\hline Preconditioned & & & & \\
\hline SPF & Intravenous & $10 \mathrm{ng}^{*}$ & 10 & 1.08 \\
\hline
\end{tabular}

Mice challenged subcutaneously with $2,5,10,50$, and $100 \mu \mathrm{g}$ C5LPS and additional challenges of 200 and $500 \mu \mathrm{g}$ in SPF animals. Entire small intestine harvested $24 \mathrm{~h}$ after LPS challenge from five controls and five challenged animals and cultured quantitatively for marker organism (Salmonella 885SR). Enhancement of bacterial growth given as $\log _{10}$ counts over unchallenged controls. In SPF and conventional mice 885SR was given as a marker organism at time of LPS challenge.

* For intravenous dose response LPS was given as three separate injections at 60 -min intervals at levels $1 \mu \mathrm{g}$ or lower.

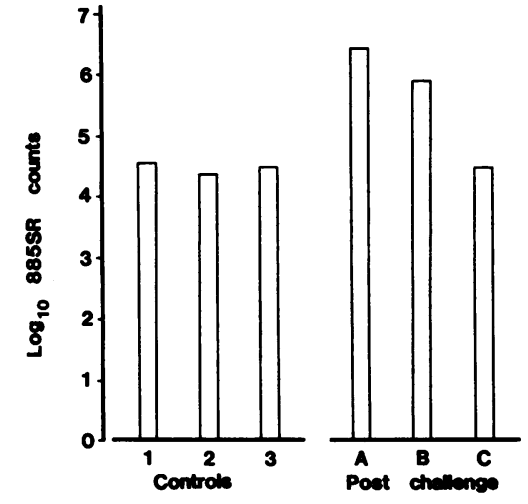

Figure 5. Effect of transfer of post C5LPS challenge plasma to 885SR preconditioned mice on quantitation of 885SR from the small intestinal wall $24 \mathrm{~h}$ later. Controls: 1 , No challenge; 2, plasma from SPF mice; 3 , plasma from 885SR preconditioned mice. Intravenous saline had similar results (not shown). Postchallenge:

$A$, fresh pooled plasma. $B$, pooled plasma kept on ice for $3 \mathrm{~h}$. $C$, pooled plasma after absorption by Sepharose IVB coupled to antibody to C5LPS.

preparations of the small intestine and colon of these mice showed vascular endothelial damage in $30-50 \%$ of lamina propria blood vessels in the upper $3 \mathrm{~cm}$ of the small intestine when LPS was given intragastric and in the distal $3 \mathrm{~cm}$ of the colon when LPS was administered by enema (Fig. 7).

\section{Discussion}

Bacterial endotoxins and LPS have a variety of biological effects in mammalian systems. Research has concentrated on the role of LPS in endotoxic shock, particularly associated with septicemia and on the modulation of the immune system and other mechanisms of resistance to infection $(15,16)$. The present results show that parenteral administration of LPS to mice caused a vascular lesion in the intestinal mucosa with fluid accumulation in the gut lumen leading to diarrhea. This lesion was dose related and dependent on the presence of gram negative gut flora, since it could be produced by smaller doses of LPS in either conventionalized mice or SPF mice preconditioned with an enteral infection a week earlier by Salmonella 885 , a gram negative invasive organism. The vascular lesion was induced by a variety of LPS, but not by cell wall preparations from gram positive organisms or Bacteroides. The exu-

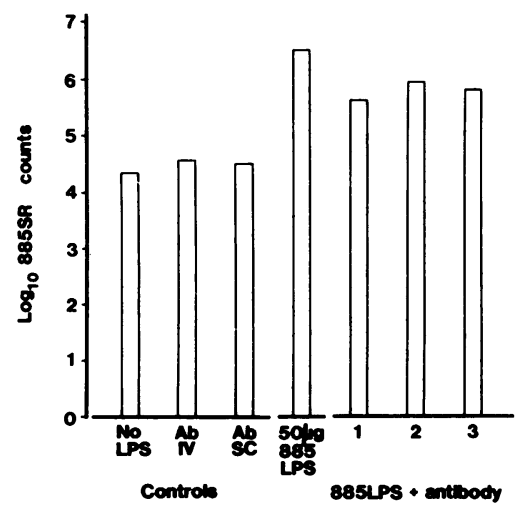

Figure 6. Effect of antibody to 885LPS on subcutaneous challenge with 885LPS in 885SR preconditioned mice. Quantitation of 885SR in small intestinal wall $24 \mathrm{~h}$ after subcutaneous challenge. Controls: No LPS, SPF mice infected with 88SR $8 \mathrm{~d}$ earlier; Ab IV, SPF mice infected with $885 \mathrm{SR}$ and challenged with 885 antibody IV on day 7 ;

AbSC, SPF mice infected with 885 SR and challenged with 885 antibody SC on day 7 . SPF mice infected with 885 SR and challenged with $50 \mu \mathrm{g} 885 \mathrm{LPS}$ subcutaneously on day $7,885 \mathrm{LPS}+$ antibody: 1 , 885LPS and antibody complexed in vitro. 2, 885LPS subcutaneously antibody IV at the same time. $3,885 \mathrm{LPS}$ subcutaneously antibody IV half an hour earlier. 
Table II. LPS Antibody or Polymyxin B Reduces Severity of LPS-induced Lesion

\begin{tabular}{llc}
\hline \multicolumn{1}{c}{ Type of challenge } & $\begin{array}{c}\text { No. sick in } \\
\text { groups of } 5 \text { mice }\end{array}$ & $\begin{array}{c}\text { Mean bacterial } \\
\text { recovery in small } \\
\text { intestinal wall } 24 \mathrm{~h} \\
\text { postchallenge }\end{array}$ \\
\hline Unchallenged control & & $\log _{10}$ counts \\
885LPS & 0 & 4.70 \\
885LPS + Anti-885 & 5 & 6.52 \\
Unchallenged control & 3 & 5.65 \\
C5LPS & 0 & 4.51 \\
C5LPS + Anti-C5 & 5 & 7.67 \\
C5LPS + Anti-R595 & 1 & 5.88 \\
C5LPS + Anti-lipid A & 1 & 4.83 \\
C5LPS + Polymyxin B & 1 & 4.71 \\
& 1 & 4.73 \\
\hline
\end{tabular}

SPF mice were preconditioned $7 \mathrm{~d}$ before LPS challenge by giving $885 \mathrm{SR}$ orally. $50 \mu \mathrm{g}$ of LPS alone or as complex with antibody or polymyxin B were given subcutaneously to groups of five mice. Small intestine harvested and counted for recovery of 885SR $24 \mathrm{~h}$ later.

dation of fluid allowed the proliferation of a variety of bacteria, including anaerobes, if present in the intestinal tract. The central role of LPS in the causation of the lesion was established by the failure to transfer the lesion to recipient mice by postchallenge plasma from which LPS had been removed by affinity chromatography. The lipid A moiety of LPS is probably the effector of this lesion since the LPS action could be blocked by treating LPS with polymyxin B or antisera to rough strains of Salmonellae (R595) or lipid A. It is now accepted that biological effects of LPS are due to its lipid A moiety (15).

Endotoxins can increase resistance to infection or heighten susceptibility depending on experimental conditions (15). Sev-

Table III. LPS Challenge Enhances the Growth of Bacteria Present in the Intestine

\begin{tabular}{|c|c|c|c|c|}
\hline \multirow[b]{3}{*}{ Organisms } & \multicolumn{4}{|c|}{$\begin{array}{l}\text { Enhancement over unchallenged } \\
\text { controls } 10^{10} \text { counts }\end{array}$} \\
\hline & \multicolumn{2}{|c|}{ Small intestine } & \multicolumn{2}{|c|}{ Colon } \\
\hline & Lumen & Wall & Lumen & Wall \\
\hline Salmonella 885 & 4.44 & 2.97 & 3.54 & 3.56 \\
\hline S. typhimurium LT2 & 1.36 & 1.84 & 3.33 & 4.57 \\
\hline S. typhimurium C5 & 3.13 & 1.08 & 3.04 & 3.56 \\
\hline V. cholera 569B & 1.67 & 0.33 & 1.69 & 0.00 \\
\hline$H$. influenzae & 1.12 & 1.41 & 1.56 & 1.41 \\
\hline S. flexneri & 4.38 & 3.73 & 3.40 & 3.55 \\
\hline L. plantorum & 3.29 & 2.68 & 1.48 & 2.49 \\
\hline B. fragilis & 1.84 & 1.68 & 0.94 & 1.00 \\
\hline
\end{tabular}

Groups of 10 conventionalized mice were given the marker bacteria orally and half the group challenged with C5LPS within half an hour. Intestinal luminal contents and wall harvested $24 \mathrm{~h}$ later and bacteria quantitated on streptomycin-containing plates. Results expressed as mean enhancement of bacteria in challenged animals compared to unchallenged controls.
Table IV. LPS and OMP from Aerobic Gram Negative Bacteria Induce the Lesion while Cell Walls from Anaerobes and Gram Positive Bacteria was Ineffective

\begin{tabular}{ccc}
\hline Type of challenge & $\begin{array}{c}\text { No. of sick mice } \\
\text { in groups of } 5\end{array}$ & $\begin{array}{c}\text { Mean enhancement of } \\
\text { bacteria over controls }\end{array}$ \\
\hline $\log _{10}$ counts
\end{tabular}

$\begin{array}{lll}\text { LPS preparation } & & \\ \text { S. typhimurium C5 } & 5 & 3.78 \\ \text { Salmonella } 885 & 5 & 1.78 \\ \text { Vibrio cholera 569B } & 4 & 1.11 \\ \text { S. flexneri } & 4 & 1.57 \\ \text { OMP or cell wall preparations } & & \\ \text { S. typhimurium C5 } & 5 & 2.28 \\ \text { Salmonella } 885 & 5 & 1.21 \\ \text { H. influenzae } & 4 & 0.94 \\ \text { B. fragilis } & 0 & 0 \\ \text { B. cereus } & 0 & 0 \\ \text { L. plantorum } & 0 & 0\end{array}$

Groups of five SPF mice preconditioned with 885 SR $7 \mathrm{~d}$ earlier were challenged with $50 \mu \mathrm{g}$ of each preparation and the bacterial recovery $24 \mathrm{~h}$ later from small intestinal wall quantitated and compared to unchallenged controls.

eral infections have been shown to increase the susceptibility of animals to the harmful effects of LPS (17-19). Among the various biological effects of LPS, its action on vascular endothelium is particularly relevant to the study reported here. LPS in large amounts can directly damage and strip off the vascular endothelium $(20,21)$. Local application of small amounts of LPS can sensitize the vascular endothelium and a subsequent LPS challenge can produce vascular lesions with fluid exudation (10). This phenomenon, the local Shwartzman reaction, was initially reported in the rabbit skin (22), but recent reports indicate that the vasculature of the kidney is also susceptible to such reactions (23).

Studies on the mechanism of pathogenesis of the Shigella group of organisms during the first decade of this century showed that the infusion of filtered broths or heat-killed cultures of Shigella produced, in addition to a neurotoxic syndrome, hemorrhagic enteritis in a variety of experimental animals (24-28). A careful analysis of these reports suggests that while the neurotoxic syndrome can be ascribed to the Shiga toxin (29), the endotoxin content of these preparations could also have contributed to the hemorrhagic enteritis. The work of Sanarelli in the 1920s also suggests that endotoxin-induced diarrhea was a possibility (30). There is very little in the literature regarding the effects of LPS on the gut until 1962, when a group of Japanese workers showed that parenteral administration of LPS preparations to mice, led to proliferation of gastrointestinal luminal bacteria (31). Subsequent work clearly established that this enhancement of bacterial growth was secondary to fluid exudation, since the bacterial growth could be suppressed by enteral administration of unabsorbable antibiotics like Neomycin (11).

A clinical relevance for this effect of LPS was suggested by the observation of the vascular lesion in the rectal mucosa of adults with acute diarrhea in southern India (6). The vascular lesions in the mice in the present study closely resembles the 

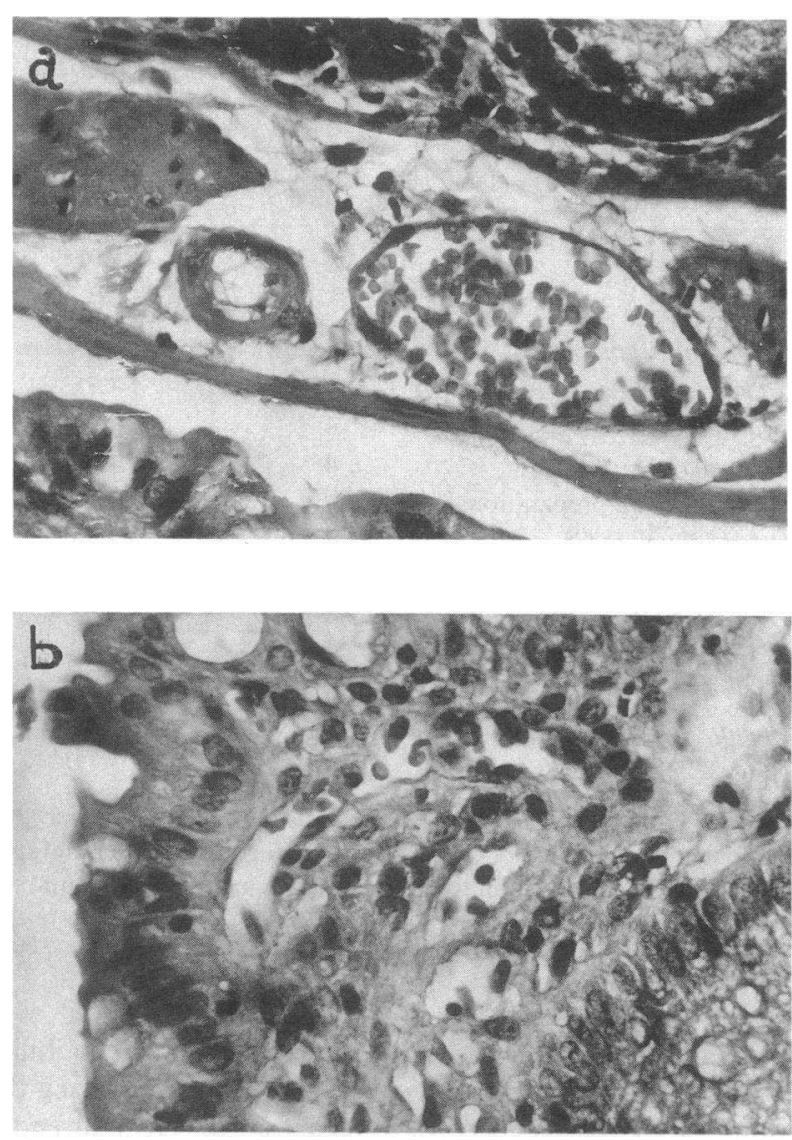

Figure 7. Effect of $1 \mathrm{mg}$ C5LPS given as enema on colonic mucosal blood vessels $24 \mathrm{~h}$ later $(\times 470)$. (a) Lamina propria venule with damaged endothelium and congestion. (b) Submucosal capillary with large damaged endothelial cell nuclei and congestion. These changes were present only in scattered vessels.

vascular lesions reported in the patients. The dose response in the mice is similar to the relationship between the prevalence of the vascular lesion and the clinical severity of illness (6). Based on the patient data it was hypothesized that, since the gut vasculature is presensitized by LPS absorption, in the event of acute diarrhea a further LPS challenge, either played a causal role in pathogenesis or had a secondary effect determining the severity of clinical illness (7). The results reported here establish that in an animal model, parenteral LPS challenge can damage the sensitized gut vasculature and lead to fluid exudation and diarrhea.

It is necessary to consider how an LPS challenge may produce diarrhea in the clinical situation. Mice challenged with large doses of LPS enterally did not develop diarrhea, but there were scattered foci of vascular damage in the areas of the gut presumably exposed to the highest concentration of LPS. The absorption of LPS from the mouse intestine is slow and in small amounts (32), which may explain the localized vascular lesion and the absence of significant fluid exudation with enteral challenge. There are several possible mechanisms by which LPS could play a role in clinical acute diarrhea. Gram negative flora of the intestinal tract could be lysed, by mechanisms such as phage, releasing large quantities of LPS in close proximity of the epithelial lining, which could then be absorbed and initiate the vascular lesion. It is also possible that gram negative bacteria with penetrating potential may be "sampled" by the Peyer's patches and other gut associated lymphoid tissue. Their digestion by macrophages could release small amounts of LPS within the mucosa, which could then initiate the vascular lesion and fluid exudation. The exudation would encourage further bacterial proliferation to perpetuate the process. It is also possible that diarrhea itself may destabilize the epithelioluminal barrier of the intestinal tract and enhance LPS absorption, which could then initiate the vascular lesion with the additional fluid exudation leading to increased severity of diarrhea. Thus the results of the present study suggest that LPS could both be an initiator of diarrhea and a determinant of clinical severity of illness. This would be a hitherto undescribed mechanism in the pathogenesis of acute diarrhea.

\section{Acknowledgments}

The skilled technical help of Mr. J. Mackrill is gratefully acknowledged.

The Wellcome Research Unit is supported by The Wellcome Trust, London, U.K. V. I. Mathan and M. Mathan were recipients of Wellcome Trust Senior Fellowships to work in Adelaide. This work was also supported by research funds of the Department of Microbiology and Immunology of The University of Adelaide.

\section{References}

1. Black, R. E. 1985. Relative importance of enteropathogens affecting humans. In Infectious diarrhoea in the young. S. Tzipori, editor. Excerpta Medica, Amsterdam. 365-370.

2. Rajan, D. P., and V. I. Mathan. 1982. Prevalence of Campylobacter fetus subsp. jejuni in healthy populations in southern India. $J$. Clin. Microbiol. 15:744-751.

3. Ko, K. W. 1985. Overview of the enteric pathogens of diarrhoea in a pediatric population in Korea: the role of enterotoxigenic $E$. coli, rotavirus and other bacterial pathogens. In Infectious Diarrhoea in the Young. S. Tzipori, editor. Excerpta Medica, Amsterdam. 61-63.

4. Moe, K. 1985. Epidemiology of acute diarrhoea in Burma. In Infectious Diarrhoea in the Young. S. Tzipori, editor. Excerpta Medica, Amsterdam. 99-103.

5. Mathan, V. I., and D. P. Rajan. 1986. The prevalence of bacterial intestinal pathogens in a healthy rural population in southern India. $J$. Med. Microbiol. 22:93-96.

6. Choudari, C. P., M. Mathan, D. P. Rajan, R. Raghavan, and V. I. Mathan. 1985. A correlative study of etiology, clinical features and rectal mucosal pathology in adults with acute infectious diarrhoea in southern India. Pathology. 17:443-450.

7. Mathan, M., and V. I. Mathan. 1985. Local Shwartzman reaction in the rectal mucosa in acute diarrhoea. J. Pathol. 146:179-188.

8. Ravin, H. A., D. Rowley, C. R. Jenkins, and J. Fine. 1960. On the absorption of bacterial endotoxins from the gastrointestinal tract of the normal and shocked animals. J. Exp. Med. 112:783-792.

9. Nolan, J. P., D. R. Hare, J. J. McDevitt, and M. V. Ali. 1977. In vitro studies of intestinal endotoxin absorption. I. Kinetics of absorption in the isolated everted gut sac. Gastroenterology. 72:434-439.

10. Movat, H. Z. 1983. The local Shwartzman phenomenon. An experimental model for microcirculatory injury induced by endotoxin. Surv. Synth. Pathol. Res. 1:241-250.

11. Rowley, D., and V. Marneerushapisal. 1983. Local cell mediated antibacterial immunity in the intestine. In Regulation of the Immune Response. P. L. Ogra and D. M. Jacobs, editors. Karger, Basel. 223-231.

12. Homan, A. W., G. Schmidt, and D. Rowley. 1978. Intestinal colonisation and virulence of Salmonellae for mice. Infect. Immun. 22:763-770. 
13. Westphal, O., O. Luderitz, and F. Bister. 1952. Uber die Extraktion von Bakterien mit Phenol/Wasser. Z. Naturforssh. 73:148155.

14. Konowalchuk, J., J. I. Speirs, and S. Stavric. 1977. Vero response to a cytotoxin of Escherichia coli. Infect. Immun. 18:775-779.

15. Morrison, D. C., and R. J. Ulevitch. 1978. The effects of bacterial endotoxins on host mediation systems. Am. J. Pathol. 93:526-617.

16. Morrison, D. C., and J. L. Ryan. 1979. Bacterial endotoxins and host immune response. Adv. Immunol. 28:293-450.

17. Suter, E. 1984. Hyper reactivity to endotoxin after infection with BCG. J. Immunol. 92:49-54.

18. Ferluga, J., M. J. Doenhoff, and A. C. Allison. 1979. Increased hepatotoxicity of bacterial lipopolysaccharide in mice infected with Schistosoma mansoni. Parasite Immunol. 1:289-294.

19. Ferrante, A., R. F. Carter, J. Ferluga, and A. C. Allison. 1984. Lipopolysaccharide hyper reactivity of animals infected with Trypanosoma lewisi or Trypanosoma musculi. Infect. Immun. 46:501-506.

20. McKay, D. G., W. Margaretten, and I. Csavossy. 1966. An electronmicroscopic study of the effects of bacterial endotoxin on the blood-vascular system. Lab. Invest. 15:1815-1829.

21. Gaynor, E. 1971. Increased mitotic activity in rabbit endothelium after endotoxin. Lab. Invest. 24:318-320.

22. Shwartzman, G. 1928. A new phenomenon to local skin reactivity to B. typhosus culture filtrate. Proc. Soc. Exp. Biol. Med. 25:560-561.

23. Raji, L., W. F. Keane, and A. F. Michael. 1977. Unilateral
Shwartzman reaction: Cortical necrosis in one kidney following in vivo perfusion with endotoxin. Kidney Int. 12:91-95.

24. Flexner, S. 1900. On the etiology of tropical dysentery. Bull. Johns Hopkins Hosp. 11:231-242.

25. Conradi, H. 1903. Uber losliche aseptische Autolyse erhlatene Giftstoffe von Ruhr-und Typhus-bazillen. Dtsch. Med. Wochenschr. 20:26-28.

26. Neisser, M., and K. Shiga. 1903. Uebes freie Recepteress von Typhus- und Dysenterie-Bazillen und ubes das Dysenterie-toxin. Dtsch. Med. Wochenschr. 29:61.

27. Todd, C. 1904. On a dysentery toxin and antitoxin. J. Hyg. 4:480-494.

28. Pfeiffer, R., and E. Ungerman. 1909. Zur Antitoxin psage beider dysenteric. Zentralbl. Bakteriol. Parasiten kD. Infektionskr. Hyg. Abt. 1. Orig. 50:534-541.

29. Keusch, G. T., A. Donohue-Rolfe, and M. Jacewicz. 1982. Shigella toxin(s): Description and role in diarrhoea and dysentery. Pharmacol. Ther. 15:403-438.

30. Sanarelli, G. 1924. De la pathogenie du cholera (neuvieme memoire). Le Cholera Experimentale. Annal. Inst. Pasteur (Paris). 38:11-72.

31. Ushiba, D., T. Sugiyama, and M. Nakane. 1962. Changes in the intestinal flora of mice following administration of bacterial endotoxins. Jpn. J. Microbiol. 6:69-78.

32. Lim, P. L., and D. Rowley. 1985. Intestinal absorption of bacterial antigens in normal adult mice. II. A comparative study of techniques. Int. Arch. Allergy Appl. Immunol. 76:30-36. 